\section{Surfaces and Interfaces Section of CMD}

The Surfaces and Interfaces Section Committee has recently met on the occasion of the big vacuum and surface jamboree in Cannes. This latter congress, which unified the International Vacuum Congress (IVC), the International Conference on Solid Surfaces (ICSS), and the European Conference on Solid Surfaces (ECOSS), will certainly remain in the memories of the participants. Cannes was beautiful as usual, but in spite of a written agreement dated 1977, the conference with 1500 participants could not be held in the "Palais des Festivals" (situated conveniently for the beach and close to the city centre) and at a few days notice, was transferred to an agglomeration of circus tents outside the city, in the immediate vicinity of the local airport. The organizers did their best to remedy the situation, for example by offering a free bar, which was a real relief at temperatures above $30^{\circ} \mathrm{C}$, in the "exhibition tents", and by providing an extra lunch tent. For some of us, it was an exciting experience to see celebrities of science enjoying their lunch from the asphalt ground of a public parking lot. In the lecture tents, where the unusual acoustics allowed us to listen to two lectures simultaneously, we were not surprised to see participants wearing T-shirts with the slogan "Circus - Non Merci".

In spite of the adverse circumstances, the scientific and technical standard of the conference remained at a high level, but at the Surface and Interface Section Committee the question was raised as to whether the combination of ECOSS and the Vacuum Congress is desirable in the future. Remember that IVC and ICSS are sponsored by IUVSTA, the International Union of Vacuum Science, Technique and Applications. ECOSS, on the other hand, originated historically from annual national surface science meetings held in France, Germany, the Netherlands and the United
Kingdom, and is cooperatively sponsored by IUVSTA and the EPS Surfaces and Interfaces Section. While ICSS emphasizes a three-yearly evaluation of the progress in the field, ECOSS concentrates on recent results and current research. For ECOSS participants, the marriage with the big vacuum congress had some unpleasant consequences such as very early submission deadlines, high cost, and a change in the proceedings series. With these points in mind, the Committee passed a resolution not to combine ECOSS with the next IVC/ ICSS to be held in Madrid in 1983. As it was felt undesirable to have two supranational surface science meetings in Europe in 1983, the Committee recommended that no ECOSS be held in that year and to restart the series by ECOSS 6 in the spring of 1984 .

Another topic discussed during the Committee meeting was the organization and sponsoring of Europhysics summer schools and study meetings. In 1981 a time-slot for a summer school was offered to the Section in the "Ettore Majorana" Centre in Erice, Sicily. A tentative programme for such a school was forwarded to the Centre earlier and accepted. The Committee was very happy to find two experienced scientists who agreed to direct the course, namely G. Benedek, Milan and U. Valbusa, Genoa. The summer school has the provisional title "Dynamics of GasSurface Interactions" and will take place in the first two weeks of July 1981. It will cover a wide range of experimental and theoretical aspects of the gas-surface interaction, with an emphasis on dynamical problems in the scattering process, presented by scientists of international reputation. For further information, please contact one of the course directors:

\section{Dr. G. Benedek}

Istitute di Fisica dell'Università

Via Celoria 16

Milan 20133, Italy

or

Dr. U. Valbusa

University of Genova

Viale Benedetto XV 5

Genova 16100 , Italy

It is hoped that this summer school will be the first in a series of schools sponsored by the Section and held, for example, every two or three years.

The Committee had received a proposal from M. Sunjic, Zagreb, to organize a workshop-type study meeting in Dubrovnik, Yugoslavia, around October 1981. The proposed topic was in the area of surface reaction dynamics (title not yet confirmed). This field is presently developing at a rapid rate, and it appears that a promising link can be made here between chemical reaction kinetics and a physical description of the microscopic processes involved. The Committee recognized the timeliness and desirability of such a study meeting, which follows a series of similar workshops held at various places in Europe, and unanimously agreed to award the sponsorship for a Europhysics Study Conference. Attendance will be limited and mainly by invitation.

The Surfaces and Interfaces Section Committee is presently at a renewal stage after its initial three years of existence. Elections will be held in the November/ December timeframe for the next three year term. Nominations by the Chairman of the Condensed Matter Division have been published in the September issue of Europhysics News. Please note that all Section members are invited to make additional nominations (supported by six members), which have to arrive at the EPS Secretariat by 14 November.

May I finally call your attention to the scientific articles published in Europhysics News. These are intended to highlight recent developments which could be of in terest to a wide part of the physics community. Surface and Interface science has been somewhat under-represented in past issues, and the Section will make an attempt to change this situation. In this context, I would appreciate any suggestions for a topic or an author from any member of the Section. In this way we can contribute to maintaining a high level of generalinterest articles in Europhysics News.

\section{B. Feuerbacher}

\section{Chairman -}

\section{Sufaces and Interfaces Section}
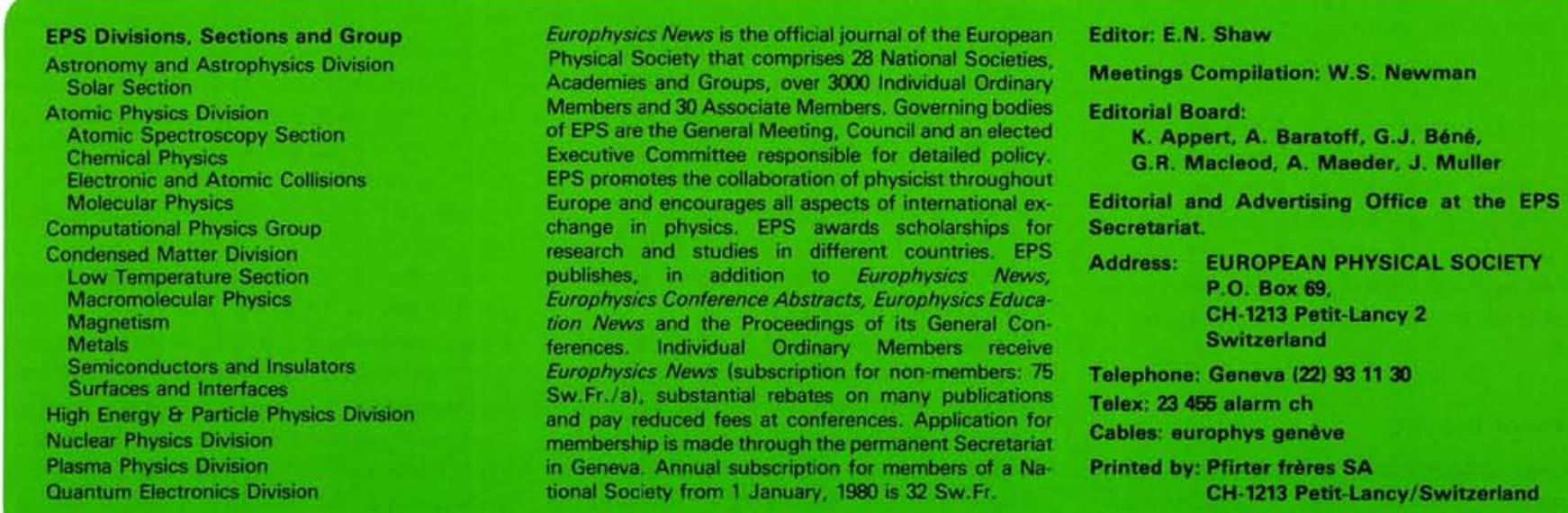